\title{
ALGORITMA KLASIFIKASI DATA MINING UNTUK MEMPREDIKSI SISWA DALAM MEMPEROLEH BANTUAN DANA PENDIDIKAN
}

\author{
SENNA HENDRIAN \\ _Program Studi Informatika \\ Universitas Idraprasta PGRI \\ Jl. Raya Tengah No. 80, Kel. Gedong, Kec. Pasar Rebo, Jakarta Timur 13760 \\ Email: Senna.hendrian@unindra.ac.id
}

\begin{abstract}
Abstrak: Pendidikan merupakan salah satu komponen kehidupan yang dapat menunjang keberhasilan seseorang menuju kehidupan yang jauh lebih baik lagi. Terutama bagi anak yang ada dalam lingkup usia wajib belajar. akan tetapi tidak semua anak wajib belajar dapat mengikuti pendidikan, karena beberapa faktor penyebab, salah satunya adalah masalah biaya pendidikan. Untuk mengatasi permasalahan yang ada, maka sekolah Bina Bangsa Mandiri menyusun program Bantuan Dana Pendidikan bagi Siswa yang dianggap kurang mampu secara strata ekonomi. Pada penelitian ini penulis menggunakan Algoritma Klasifikasi Dataminig yaitu Algoritma C4.5 untuk memprediksi siswa dalam memperoleh bantuan dana pendidikan. Sampel data diambil dari SMA Bina Bangsa Mandiri yang beralamat di Kecamatan Gunungputri Kab. Bogor. Dari hasil pengujian digunakan tes Cros Validation dan Confusion Matrix dan Kurva ROC. Hasil yang diperoleh untuk nilai Accuracy Algoritma C4.5 adalah sebesar 98,80\%, nilai untuk Precision sebesar 98,02\%, dan nilai untuk Sensitivity atau Recall sebesar 99,00\%. Dengan demikian Algoritma C4.5 merupakan algoritma dan teknik terbaik untuk Memprediksi Siswa dalam memperoleh Bantuan Dana Pendidikan.
\end{abstract}

Kata Kunci : data mining, algoritma klasifikasi, algoritma C4.5, dana pendidikan.

Abstract: Education is one of the components of life that can support the success of a person towards life that much better again. Especially for the children that are in the scope of the age of compulsory education. but not all children can attend compulsory education, because several factors cause, one of which is the issue of tuition fees. To cope with the existing problems, then a standalone compiled Bina Bangsa School programs Help Fund education for students who are considered less capable in economic strata. In this study, the author uses the classification Algorithm Datamining Algorithm C4.5 to predict students in obtaining the help of the Education Fund. Sample data are drawn from the Upper secondary school (HIGH SCHOOL) Selfsustaining Bina Bangsa (BBM) that located in Kecamatan Gunungputri Kab. Bogor. From the results of testing and Validation of tests used Cros Confusion Matrix and ROC Curves. The results obtained for the value of Accuracy Algorithm C 4.5 is 98.80\%, a value for the Precision of $98.02 \%$, and the value for Sensitivity or Recall of $99.00 \%$. Thus the algorithm C 4.5 is the best techniques and algorithms to predict Students in obtaining the help of the Education Fund. Keywords : data mining, algorithms of classification, algorithm C 4.5, the education fund

\section{PENDAHULUAN}

Ilmu pengetahuan seseorang dapat diperoleh melalui pendidikan di sekolah, karena dengan bersekolah kita akan mampu mewujudkan keberhasilan dan kesuksesan dalam kehidupan. Namun empirik dilapangan menunjukan bahwa ekonomi yang terbatas bagi sebagian orang tua menjadi faktor penghambat dalam mewujudkan kesuksesan anaknya, sehingga tidak semua anak usia wajib belajar dapat mengikuti pendidikan di sekolah. Untuk mengatasi permasalahan yang ada, yaitu melalui program beasiswa pendidikan. Yayasan Bina Bangsa Mandiri merupakan salah satu lembaga pendidikan dengan mempunyai tiga Sekolah, yaitu SMP, SMA dan SMK Bina Bangsa Mandiri, dimana sekolah ini mempunyai program Bantuan Dana Pendidikan bagi Siswa yang 
dianggap kurang mampu secara strata ekonomi. Namun sudah tentu syarat dan ketentuan berlaku, dan semua kriteria pemilihan penentuan siswa memperoleh bantuan dana pendidikan itu dilakukan berdasarkan data siswa yang ada, kemudian dianalisis secara manual, namun terkadang hasil yang diperoleh tidak sesuai. Dengan demikian pada penelitian ini penulis menggunakan Algoritma Klasifikasi Dataminig yaitu Algoritma C4.5 untuk memprediksi siswa dalam memperoleh bantuan dana pendidikan. Sampel data diambil dari Sekolah Menengah Atas (SMA) Bina Bangsa Mandiri yang beralamat di Kecamatan Gunungputri Kabupaten Bogor.

Data mining telah banyak menarik perhatian di masyarakat dalam beberapa tahun ini, karena mampu mengubah data yang luas dan jumlah yang besar menjadi informasi yang berguna dan pengetahuan. Informasi dan pengetahuan yang diperoleh dapat digunakan untuk mengaplikasikan seperti analisis pasar, deteksi penipuan, dan retensi pelanggan, untuk pengendalian produksi dan ilmu pengetahuan eksplorasi (Han \& Kember, 2007).

Sementara menurut Turban, E. dkk 2005, data mining merupakan sebuah proses yang menggunakan teknik statistik, matematika, kecerdasan buatan, dan machine learning untuk mengekstrasi dan mengidentifikasi informasi yang bermanfaat dan pengetahuan yang terkait dari berbagai database besar.

Klasifikasi adalah tipe analisis data yang dapat membantu orang menentukan kelas label dari sampel yang ingin di klasifikasi. Klasifikasi merupakan Metode supervised learning, metode yang mencoba menemukan hubungan antara atribut masukan dan atribut target. Tujuan klasifikasi untuk meningkatkan kehandalan hasil yang diperoleh dari data.

Algoritma C4.5 Salah satu metode klasifikasi yang digunakan. Melibatkan konstruksi pohon keputusan, koleksi node keputusan. Setiap cabang kemudian mengarah ke node lain baik keputusan atau ke node daun untuk mengakhiri (Larose, 2005). C4.5 adalah algoritma yang mempunyai input berupa training samples berupa data contoh yang akan digunakan untuk membangun sebuah tree yang telah diuji kebenarannya dan samples yang merupakan field - field data yang nantinya akan digunakan sebagai parameter dalam melakukan klasifikasi data. Algoritma dasar dari $\mathrm{C} 4.5$ adalah sebagai berikut:

1). Pohon yang dihasilkan berupa pohon terbalik, 2). Pada tahap awal, semua contoh training adalah akar. 3). Atribut adalah kategori. 4) Contoh di partisi secara berulang berdasarkan atribut yang dipilih. 5). Atribut tes dipilih dari data heuristic atau pengukuran statistik

Tahapan algoritma $\mathrm{C} 4.5$ adalah sebagai berikut:

1). Siapkan data training. 2) Pilih atribut sebagai akar

Untuk memilih atribut akar, didasarkan pada nilai Gain tertinggi dari atribut-atribut yang ada. Untuk mendapatkan nilai Gain, harus ditentukan terlebih dahulu nilai Entropy.

Rumus Entropy:

$S=$ Himpunan Kasus

$$
\operatorname{Entropy}(S)=\sum_{i=1}^{n}-p i * \log _{2} p i
$$

n = Jumlah Partisi $S$

$p i=$ Proporsi dari Si terhadap $S$

Rumus Gain :

$$
\begin{gathered}
\operatorname{Gain}(S, A)=\operatorname{Entropy}(S)-\sum_{i=1}^{n} \frac{\left|S_{i}\right|}{|S|} * \operatorname{Entropy}\left(S_{i}\right) \\
S=\text { Himpunan Kasus } \\
A=\text { Atribut } \\
n=\text { Jumlah Partisi Atribut } \\
|\mathrm{Si}|=\text { Jumlah Kasus pada partisi ke- } i \\
|\mathrm{~S}|=\text { Jumlah Kasus dalam } S
\end{gathered}
$$


Decission Tree atau Pohon Keputusan adalah struktur sederhana yang dapat digunakan sebagai pengklasifikasi. Referensi penting dalam pengerjaan aslinya adalah Classification and Regression Tree oleh Breiman et al.

Pada pohon keputusan, masing-masing node internal (non-leaf) merepresentasikan sebuah variabel atribut (atribut prediksi atau fitur) dan masing-masing cabang merepresentasikan satu keadaan dari variabel ini. Masing-masing dari tiga daun (leaf) menspesifikasikan nilai yang diharapkan dari kelas variabel (variabel yang akan di prediksi). Aspek penting dari prosedur untuk membangun pohon keputusan adalah pemisahan kriteria (split criterion) termasuk kriteria untuk membuat cabang dan kriteria terakhir (stop criterion), kriteria yang digunakan untuk menghentikan pencabangan. Pohon keputusan dibuat menggunakan himpunan dari data yang digunakan sebagai data pembelajaran (training dataset). Himpunan yang berbeda yang disebut test dataset digunakan untuk melakukan pengujian untuk mengecek model. Pohon keputusan menawarkan banyak keuntungan, antara lain:

1. Fleksibilitas untuk berbagai tugas data mining, seperti klasifikasi, regresi, clustering dan seleksi fitur.

2. Cukup jelas dan mudah diikuti (ketika dipadatkan).

3. Fleksibilitas dalam menangani berbagai input data: nominal, numerik dan tekstual.

4. Adaptasi di dataset pengolahan yang mungkin memiliki kesalahan atau nilai-nilai yang hilang.

5. Kinerja prediktif tinggi untuk upaya komputasi yang relatif kecil.

6. Tersedia dalam berbagai paket data mining melalui berbagai platform

7. Berguna untuk dataset besar (dalam kerangka ensemble).

Cross Validation merupakan salah satu teknik untuk menilai/memvalidasi keakuratan sebuah model yang dibangun berdasarkan dataset tertentu. Data yang digunakan dalam proses pembangunan model disebut data latih/training, sedangkan data yang akan digunakan untuk memvalidasi model disebut sebagai data test.

Tabel 1. Confusion Matrix

\begin{tabular}{cccc}
\hline Kelas & Prediksi Yes & Prediksi No & Total \\
\hline Aktual Yes & True Positive (TP) & False Negative (FN) & Positive (P) \\
Aktual No & False Positive (FP) & True Negative (TN) & Negative (N) \\
Total & P' & N' & P+N \\
\hline
\end{tabular}

Rumus Mencari Akurasi adalah :

$$
\text { accuracy }=\frac{T P+T N}{T P+F P+T N+F N}
$$

Rumus Mencari Sentitivity atau Recall adalah :

Rumus Mencari Nilai Precision adalah :

$$
\text { sensitivity }=\frac{T P}{T P+F N}
$$

$$
\text { precision }=\frac{T P}{T P+F P}
$$

Kurva ROC (Receiver Operating Characteristic) menunjukan akurasi dan membandingkan klasifikasi secara visual. ROC mengekspresikan confusion matrix. ROC adalah grafik dua dimensi dengan false positives sebagai garis horizontal dan true positives untuk mengukur perbedaaan performasi metode yang digunakan. ROC Curve adalah cara lain untuk menguji kinerja pengklasifikasian (Gorunescu, 2010). Selanjutnya dari grafik ROC diperoleh nilai Area Under Curve (UAC) 
Rapid Miner merupakan perangkat lunak yang dibuat oleh Dr. Markus Hofmann dari Institute of Technology Blanchardstown dan Raif Klinkenberg dari rapid-i.com dengan tampilan GUI (Graphical User Interface) sehingga memudahkan pengguna dalam menggunakan perangkat lunak ini. Perangkat lunak ini bersifat open source dan dibuat dengan menggunakan bahasa java dibawah lisensi GNU Public License dan Rapid Miner dapat dijalankan disistem operasi manapun. Dengan menggunakan Rapid Miner, tidak dibutuhkan kemampuan koding khusus, karena semua fasilitas sudah disediakan. Rapid Miner dikhususkan untuk penggunaan data mining.

\section{METODE}

Penelitian yang digunakan adalah model penelitian eksperimen. Bertujuan untuk melakukan prediksi Siswa SMA Bina Bangsa Mandiri dalam memperoleh Bantuan Dana Pendidikan dari sekolah, berdasarkan nilai akurasi dan evaluasi pada algoritma klasifikasi data mining. Penelitian ini menekankan pada teori-teori yang sudah ada, dilandasi oleh kerangka pemikiran pemecahan masalah seperti pada gambar 1 .

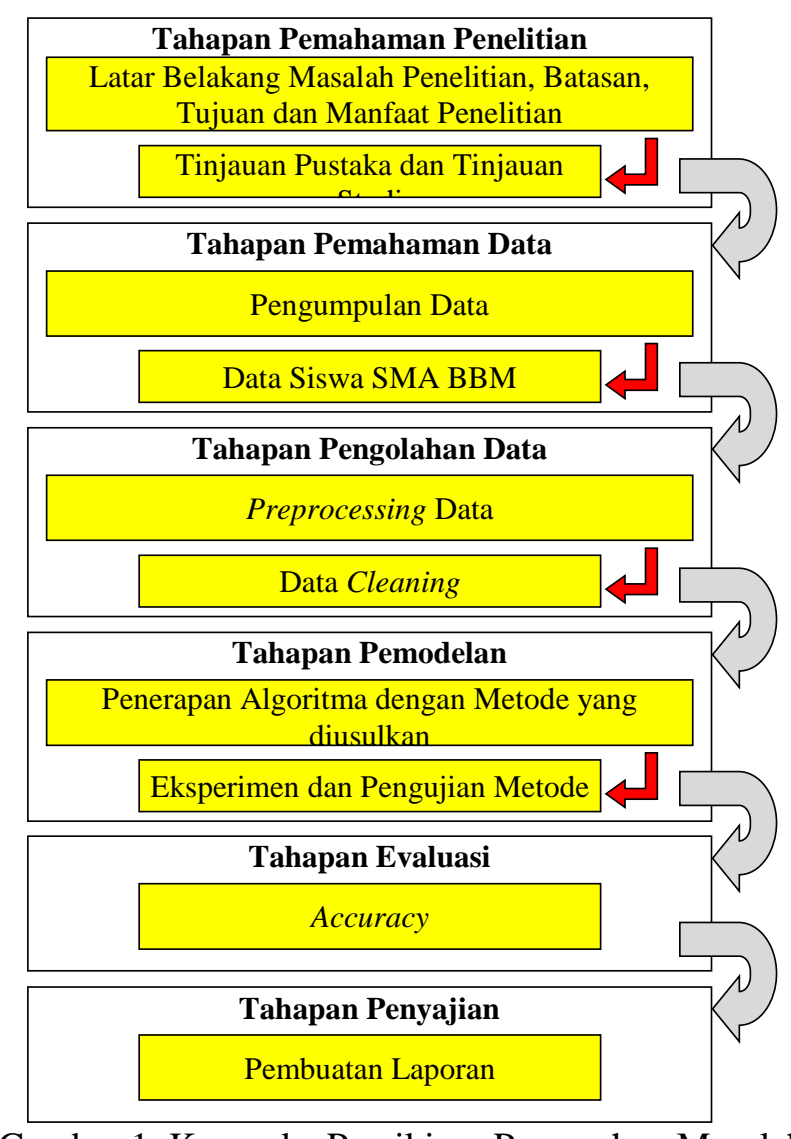

Gambar 1. Kerangka Pemikiran Pemecahan Masalah

Penelitian ini dilakukan dengan menjalankan beberapa langkah proses penelitian yaitu :

1. Pengumpulan Data

2. Pengolahan Data Awal

3. Pengukuran Penelitian

4. Analisa hasil Penerapan Algoritma

\section{HASIL DAN PEMBAHASAN}


Data yang digunakan bersumber dari data Siswa aktif SMA Bina Bangsa Mandiri dengan dengan jumlah kasus sebanyak 254 record, dan terdiri dari 37 atribut, seperti terlihat dalam gambar 2 dibawah ini:

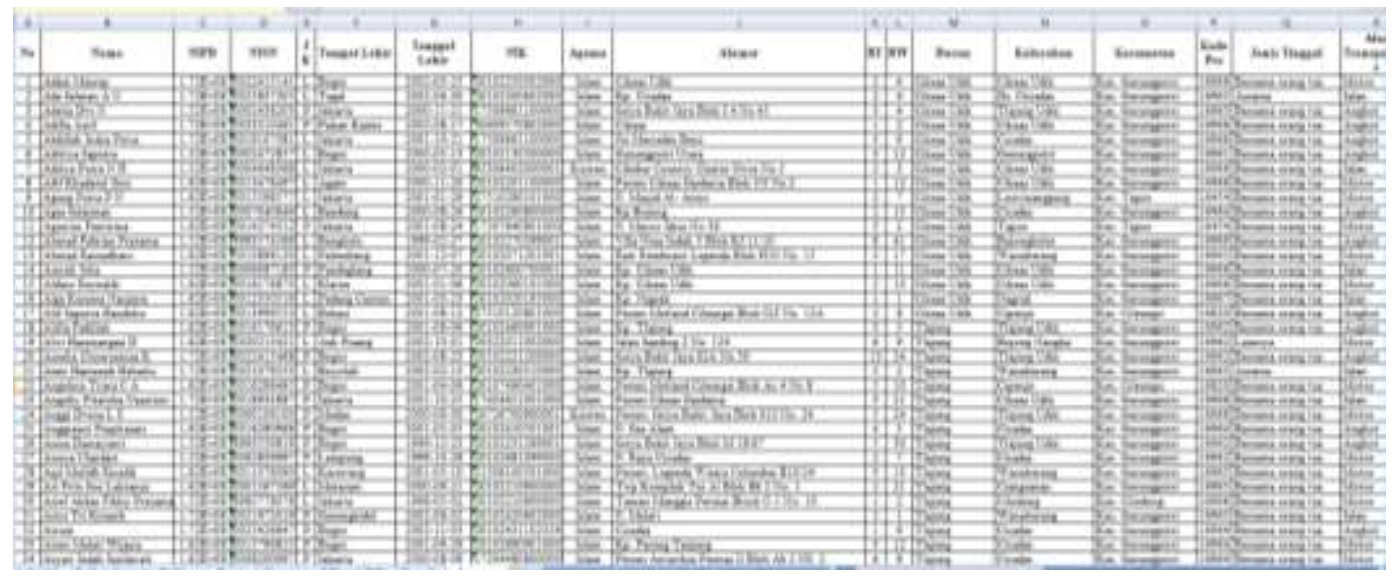

Gambar 2. Potongan Dataset

\section{Pengolahan Data Awal}

Dalam pengujian ini menggunakan rapid miner dengan operator 10-fold cross-validation untuk mendapatkan hasil accuracy dan AUC pada setiap algoritma yang diuji menggunakan dataset siswa. Berikut adalah proses Preprocessing.

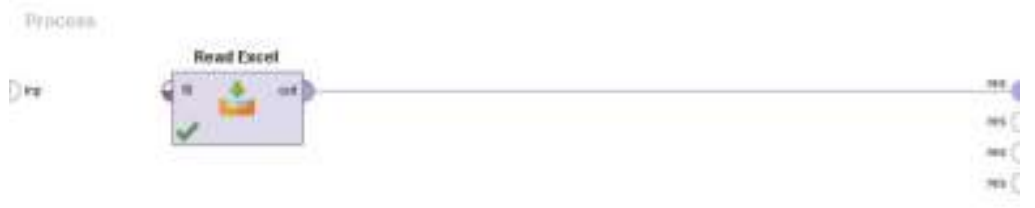

Gambar 3. Proses Preprocessing

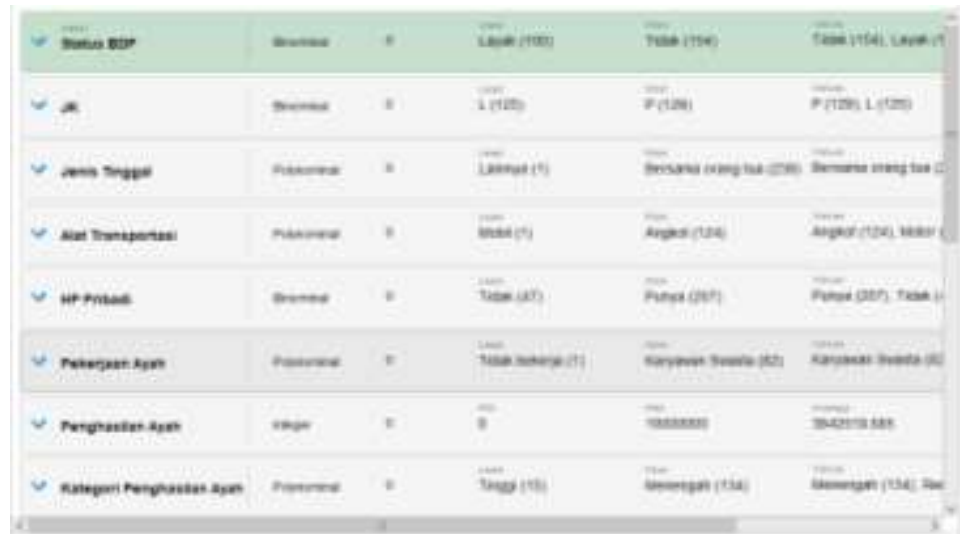

Gambar 4. Potongan Hasil Preprocessing

\section{Pengukuran Penelitian}

Berdasarkan hasil olah data melalui aplikasi Rapid Miner, maka diperoleh Confution Matrix guna mengukur tingkat akurasinya, dari algoritma $\mathrm{C} 4.5$, yaitu sebesar $\mathbf{9 8 , 8 0 \%}$, Precision sebesar $\mathbf{9 8 , 0 2 \%}$, dan Sensitivity atau Recall sebesar $\mathbf{9 9 , 0 0 \%}$, seperti yang dapat kita lihat pada gambar 5 dibawah ini. 
accuracy: $98.80 \%+/-2.56 \%$ (mikro: $98.82 \%$ )

\begin{tabular}{|l|l|l|l|}
\hline & true Layak & true Tidak & class precision \\
\hline pred. Layak & 99 & 2 & $98.02 \%$ \\
\hline pred. Tidak & 1 & 152 & $99.35 \%$ \\
\hline class recall & $99.00 \%$ & $98.70 \%$ & \\
\hline
\end{tabular}

Gambar 5. Nilai Akurasi dari Algoritma C4.5

Nilai accuracy diperoleh dari rumus : accuracy $=\frac{T P+T N}{T P+F P+T N+F N}$

$$
\text { Accuracy }=\frac{99+152}{99+1+152+2}=\frac{251}{254}=0,9881
$$

Mencari nilai Sensitivity atau Recall dengan rumus sensitivity $=\frac{T P}{T P+F N}$

$$
\text { Precision }=\frac{99}{99+1}=\frac{99}{100}=0,99
$$

Mencari nilai Precision dengan rumus precision $=\frac{T P}{T P+F P}$

$$
\text { sensitivity }=\frac{99}{99+2}=\frac{99}{101}=0,9801
$$

Area Under Curve (AUC) dari model Algoritma C4.5 dapat dilihat pada gambar 6 dibawah ini :

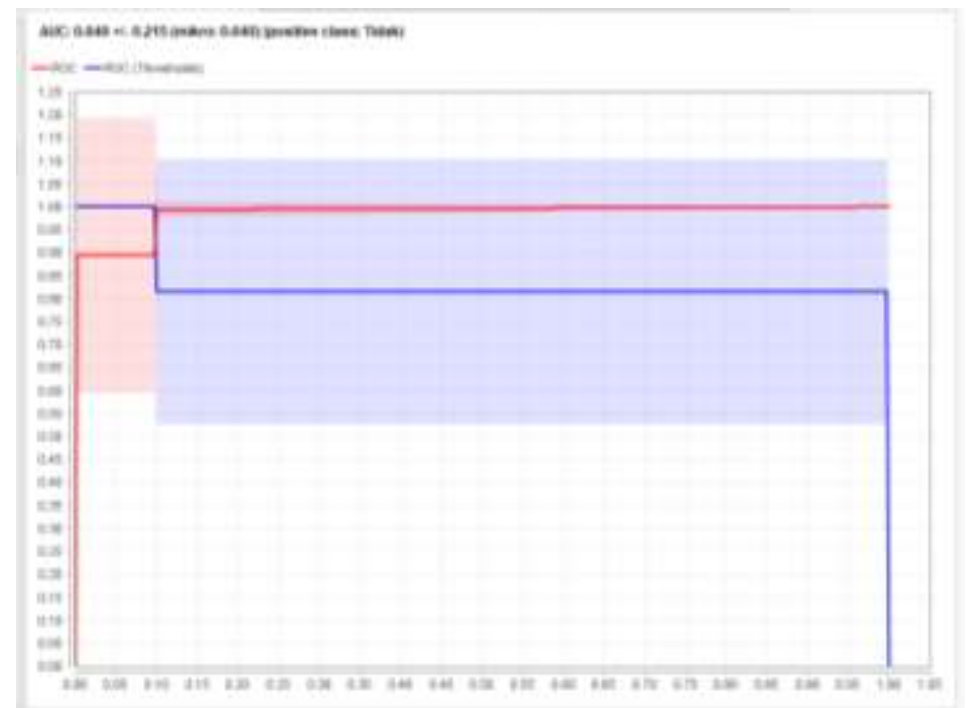

Gambar 6. AUC Algoritma C4.5

Penjelasan Area Under Curve (AUC) :

- Jika kurva yang dihasilkan mendekati garis baseline atau garis yang melintang dari titik 0,0, maka dapat dikaterikan jelek. 
- Sebaliknya jika kurva mendekati titik 0,1 atau diatasnya maka dikategorikan Bagus.

Tabel Evaluasi hasil pengolahan data dengan menggunakan metode yang diusulkan dapat dilihat pada tabel dibawah ini :

Tabel 2. Evaluasi Hasil Pengolahan data dengan Metode yang diusulkan

\begin{tabular}{ccccc}
\hline No & Metode & Accuracy & Precision & Sensitivity atau Recall \\
1 & Algoritma C4.5 & $\mathbf{9 8 , 8 0 \%}$ & $\mathbf{9 8 , 0 2 \%}$ & $\mathbf{9 9 , 0 0 \%}$ \\
\hline
\end{tabular}

\section{Analisa Hasil Penerapan Algoritma}

Melalui data yang disajikan pada table 1 di atas, telah menghasilkan sebuah model pohon keputusan, dapat dilihat pada gambar 7:

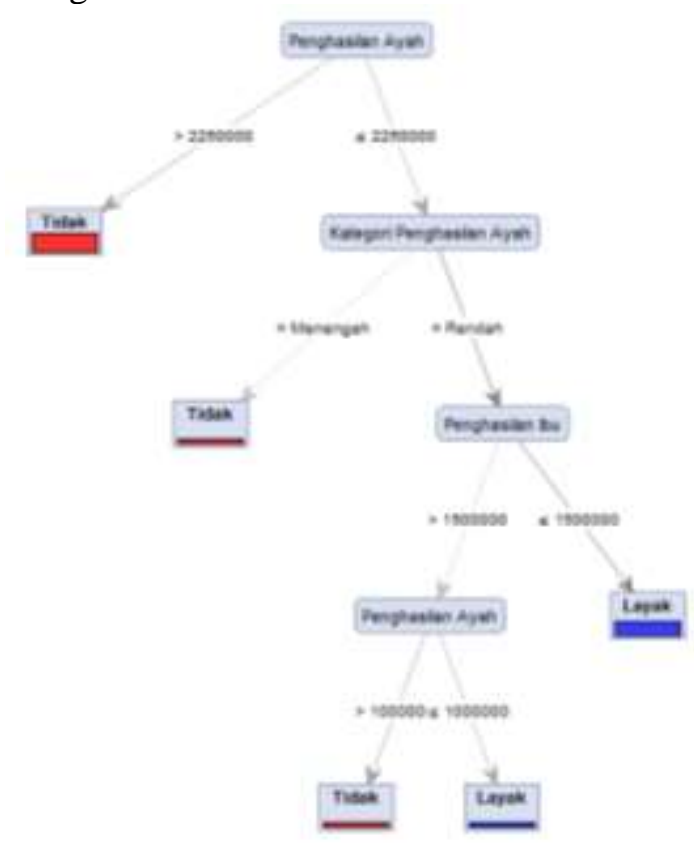

Gambar 7. Pohon Keputusan yang dihasilkan

Penjelasan dari Model Pohon Keputusan yang dihasilkan:

Yang menjadi atribut akar adalah Penghasilan ayah, dimana memiliki dua kelompok kelas atau range antara lain $>2250000$ dengan $<=2250000$. Diantara dua kelompok kelas tersebut, kelompok kelas penghasilan ayah >2250000 sudah mengklasifikasikan kasus kedalam keputusan Pilihan yang Tidak, sedangkan untuk kelompok kelas penghasilan ayah $<=2250000$ itu perlu dilakukan perhitungan, guna menentukan node cabang selanjutnya. Begitu juga penjelasan untuk tiap node dibawahnya.

Berikut adalah rule yang dihasilkan dari pohon keputusan, dapat dilihat pada gambar 8 dibawah ini : 


\section{Tree}

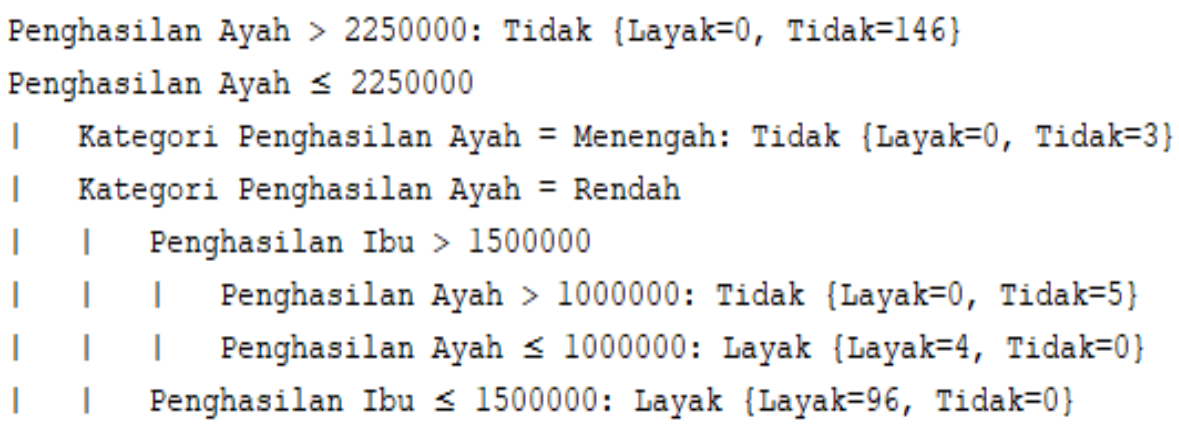

Gambar 8. Rule yang dihasilkan

\section{PENUTUP}

Simpulan

Dari hasil pengujian digunakan tes Cros Validation dan Confusion Matrix dan Kurva ROC. Algoritma C4.5 menghasilkan nilai Accuracy sebesar 98,80\%, nilai untuk Precision sebesar 98,02\%, dan nilai untuk Sensitivity atau Recall sebesar 99,00\%. Dengan demikian Algoritma C4.5 merupakan algoritma dan teknik terbaik untuk Memprediksi Siswa Dalam Memperoleh Bantuan Dana Pendidikan.

\section{Saran}

Saran untuk penelitian selanjutnya adalah dapat dilakukan sebuah komparasi dari beberapa Algoritma klasifikasi datamining, misal Algoritma C4.5 dengan Algoritma Nä̈ve Bayes atau antara Algoritma C4.5, Algoritma Nä̈ve Bayes dengan Algoritma Random Fores, sehingga dapat diketahui Algoritma yang terbaik dalam Memprediksi Siswa Dalam Memperoleh Bantuan Dana Pendidikan.

\section{DAFTAR PUSTAKA}

Breiman, L., Friedman, J. H., Olshen, R. A., \& Stone, C. J. (1984). Classification and Regression Trees. Chapman and Hall/CRC (1st ed., Vol. 19). Chapman and Hall/CRC.

Bujlow, T., Riaz, T., \& Pedersen, J. M. (2012). A method for classification of network traffic based on C5.0 machine learning algorithm. 2012 International Conference on Computing, Networking and Communications, ICNC'12, 237-241. http://doi.org/10.1109/ICCNC.2012.6167418.

Dawson, C. W. (2009). Projects in Computing and Information Systems A Student's Guide (2nd ed). Great Britain: Pearson Education.

Gorunescu, Florin. (2011). Data Mining: Concepts and Techniques. Verlag berlin Heidelberg: Springer.

Han, J., \& Kamber, M. (2007). Data Mining Concepts and Techniques. San Fransisco: Mofgan Kaufan Publisher.

Han Jiawei,Kamber, M, "Data Mining: Concepts and Techniques," New York: Morgan Kaufmann Publishers, 2001.

Han, J., Kamber, M., \& Pei, J. (2012). Data Mining: Concepts and Techniques.

Larose, D. T. (2005). Discovering Knowledge in Data. New Jersey: John Willey \& Sons, Inc.

Larose Daniel T (2006). Data Mining Methodes and Models. Hoboken. Wiley-Interscience. : John Willey \& Sons, Inc. 
Faktor Exacta 11 (3): 266-274, 2018

p-ISSN: 1979-276X

e- ISSN: 2502-339X

DOI : 10.30998/faktorexacta.v11i3.2777

Senna Hendrian - Algoritma Klasifikasi Data Mining...

Liao, S. H., Chu, P. H., \& Hsiao, P. Y. (2012). Data mining techniques and applications - A decade review from 2000 to 2011. Expert Systems with Applications, 39(12), 11303-11311. http://doi.org/10.1016/j.eswa.2012.02.063.

Turban, E., dkk, 2005, Decicion Support Systems and Intelligent Systems, Andi Offset. 